\title{
Developmental Toxicity of Endocrine Disrupters Bisphenol A and Vinclozolin in a Terrestrial Isopod
}

\author{
M. F. L. Lemos • C. A. M. van Gestel • \\ A. M. V. M. Soares
}

Received: 10 July 2009/Accepted: 15 January 2010/Published online: 11 February 2010

(C) The Author(s) 2010. This article is published with open access at Springerlink.com

\begin{abstract}
Studies of the effects of endocrine-disrupting compounds (EDCs) on invertebrates are still largely underrepresented. This work aims to fill this gap by assessing the effects of bisphenol A (BPA) and vinclozolin $(\mathrm{Vz})$ on the terrestrial isopod Porcellio scaber (common rough woodlouse). Male adult and sexually undifferentiated juvenile woodlice were exposed to the toxicants. Effects on molting regime and growth were investigated independently for males and female woodlice after sexual differentiation. Both chemicals elicited developmental toxicity to $P$. scaber by causing overall decreased growth. Nevertheless, BPA induced molting, whereas $\mathrm{Vz}$ delayed it. Although the $\mathrm{LC}_{50}$ values for juvenile and adult survival were fairly similar, juvenile woodlice showed an increased chronic sensitivity to both chemicals, and female woodlice were most the sensitive to BPA. We recommend the use of adults, juveniles, female, and male woodlice, as well as a large range of toxicant concentrations, to provide valuable information regarding differential dose responses, effects, and threshold values for EDCs.
\end{abstract}

M. F. L. Lemos $(\bowtie) \cdot$ A. M. V. M. Soares

CESAM and Department of Biology,

University of Aveiro, 3810-193 Aveiro, Portugal

e-mail: mlemos@ua.pt

A. M. V. M. Soares

e-mail: asoares@ua.pt

M. F. L. Lemos

GIRM and School of Tourism and Maritime Technology,

Polytechnic Institute of Leiria, 2524-909 Peniche, Portugal

C. A. M. van Gestel

Institute of Ecologic Science, VU University Amsterdam,

NL-1081 HV, Amsterdam, The Netherlands

e-mail: kees.van.gestel@falw.vu.nl
Endocrine-disrupting compounds (EDCs) are a structurally diverse group of chemicals that may adversely affect the health of humans and wildlife at both the individual and population levels by interacting with the endocrine system (Porte et al. 2006).

From the many studies reported in the literature about endocrine disruption (ED), only a minor fraction have investigated their effects in invertebrates; from these only $10 \%$ were conducted with terrestrial invertebrates (Oehlmann et al. 2003). This value is almost residual when restricting these studies to edaphic fauna. As such, invertebrates are a diverse group that has clearly been understudied. There is insufficient knowledge of their endocrinology, thus creating larger obstacles in the study of ED mechanisms (Oetken et al. 2004).

Woodlice are saprophytic organisms that carry a key role in organic-matter decomposition in soils, and they are ideal model test organisms for ecotoxicologic studies (Drobne 1997). Moreover, their sexual reproduction and dimorphism, their size, and their easily distinct molting stages make them suitable candidates for ED testing (Lemos et al. 2009a, 2010a).

Vinclozolin (Vz; 3-(3,5-dichlorophenyl)-5-methyl-5vinyl-1,3-oxazolidine-2,4-dione; CAS 50471-44-8) is a fungicide widely used in agriculture. It is a proven EDC that causes antiandrogenic effects due to its metabolites (Bursztyka et al. 2008). Bisphenol A (BPA; 4,4'-dihydroxy-2,2-diphenylpropane; CAS 80-05-7) is used to produce epoxy and polycarbonate resins, which are employed in the manufacture of a wide range of consumer products, such as food containers, and in medical applications. It has been shown to be an estrogen-receptor agonist (Okada et al. 2008) for which antiandrogenic properties have also been identified (Lee et al. 2003). Both compounds are included in the compounds priority list proposed by the European 
Commission (1999) and have been proven to have ecdysteroidal activity in terrestrial isopods (Lemos et al. 2009a).

Processes under endocrine regulation, such as the molting of arthropods, involve a combination of molecular, physiologic, and behavioural actions (LeBlanc 2007). Altering any of these processes may disrupt many physiologic processes, even if ED is not involved. Thus, although classical toxicity testing methodologies to assess acute and/ or chronic effects are not specifically designed to evaluate ED (e.g., growth rate and molt time and success), they can measure adverse integrative effects associated with EDCs (deFur et al. 1999). However, once specific parameters, such as hormone levels, are proven to be affected, a causal link to ED can be addressed (Barata et al. 2004).

Ecdysteroidal activity caused by the proposed compounds in P. scaber has already been shown (Lemos et al. 2009a). The importance of ecdysteroids in crustacean development is crucial, and thus there is a need to establish the causal link between exposure, ecdysteroid levels, and higher-levels of biologic organization of the affected crustacean.

\section{Materials and Methods}

\section{Test Species and Culture Procedures}

The woodlice (Porcellio scaber Latreille, 1804) came from an 8-year established laboratory culture reared as described in Lemos et al. (2009a) at $21^{\circ} \mathrm{C} \pm 1{ }^{\circ} \mathrm{C}$ under a 16 :8-hour light-to-dark photoperiod. According to the procedure adopted by Lemos et al. (2009a), synchronized juveniles (born within 2 days) weighing 4-5 mg (approximately 3 months old) and adults weighing 19-21 mg were obtained and used for the experiments.

\section{Chemicals and Preparation of Soil}

Agricultural soil from the lower Mondego valley (central Portugal), kept fallow for the last 5 years, was used in these experiments. Soil parameters are listed in Table 1. The soil was oven dried at $60^{\circ} \mathrm{C}$ for $48 \mathrm{~h}$ and immediately weighed, cooled at room temperature, and then contaminated.

BPA (Merck Schuchardt, Germany, purity $>99 \%$ ) was solubilised in methanol and mixed with soil at 10, 30, 100, 300 , and $1000 \mathrm{mg} / \mathrm{kg}$ dry soil for experiments with adults. For juvenile testing, toxicant concentrations were 10, 25, 50,100 , and $300 \mathrm{mg} / \mathrm{kg}$ dry soil. Afterward, the solvent was allowed to evaporate under a fume hood for $12 \mathrm{~h}$, and moisture content was adjusted to $20 \%(\mathrm{v} / \mathrm{w})$ with distilled water. A solvent control was prepared according to the same procedure using the same volume of methanol without BPA. This was left to dry, and moisture content
Table 1 Physicochemical and mineralogical characterization of agricultural soil from the lower Mondego valley used in the experiments on the toxicity of $\mathrm{Vz}$ and BPA to P. scaber

\begin{tabular}{ll}
\hline Parameter & Value \\
\hline $\mathrm{pH}\left(\mathrm{H}_{2} \mathrm{O}\right)$ & 7.48 \\
$\mathrm{pH}(\mathrm{KCl})$ & 7.31 \\
$\mathrm{P}\left(\mathrm{P}_{2} \mathrm{O}_{5}\right)(\mathrm{mg} / \mathrm{kg})$ & 152 \\
$\mathrm{~K}\left(\mathrm{~K}_{2} \mathrm{O}\right)(\mathrm{mg} / \mathrm{kg})$ & 180 \\
$\mathrm{Na}(\mathrm{mg} / \mathrm{kg})$ & 13 \\
$\mathrm{Ca}(\mathrm{mg} / \mathrm{kg})$ & 1478 \\
$\mathrm{Mg}(\mathrm{mg} / \mathrm{kg})$ & 53 \\
$\mathrm{Fe}(\mathrm{mg} / \mathrm{kg})$ & 16960 \\
$\mathrm{Zn}(\mathrm{mg} / \mathrm{kg})$ & 96 \\
$\mathrm{Mn}(\mathrm{mg} / \mathrm{kg})$ & 267 \\
$\mathrm{Cu}(\mathrm{mg} / \mathrm{kg})$ & 12 \\
$\mathrm{Cd}(\mathrm{mg} / \mathrm{kg})$ & $<2.8$ \\
$\mathrm{Cr}(\mathrm{mg} / \mathrm{kg})$ & 11 \\
$\mathrm{~Pb}(\mathrm{mg} / \mathrm{kg})$ & 61 \\
$\mathrm{Co}(\mathrm{mg} / \mathrm{kg})$ & $<15$ \\
$\mathrm{Ni}(\mathrm{mg} / \mathrm{kg})$ & $<14$ \\
$\mathrm{~N}$ total $(\%)$ & 0.06 \\
$\mathrm{OM}(\%)$ & 2.4 \\
$\mathrm{Clay}(\%)$ & 4.22 \\
$\mathrm{Silt}(\%)$ & 7.00 \\
$\mathrm{Sand}(\%)$ & 88.77 \\
$\mathrm{Density}\left(\mathrm{g} / \mathrm{cm}{ }^{3}\right)$ & 2.4 \\
$\mathrm{Water} \mathrm{holding} \mathrm{capacity} \mathrm{max}(\%)$ & 70 \\
\hline &
\end{tabular}

was adjusted as described previously (represented as $0^{+}$). A control was prepared with water added to dry soil.

$\mathrm{Vz}$ (Ronilan 50\% active ingredient [a.i.]; BASF AG, Germany) was added to soil at 10,30, 100, 300, and $1000 \mathrm{mg}$ a.i./ $/ \mathrm{kg}$ dry soil for adult experiments and at 5, 10, 25,50 , and $100 \mathrm{mg}$ a.i./.kg dry soil for juvenile testing. The soil moisture content was then adjusted to $20 \%(\mathrm{v} / \mathrm{w})$ with distilled water. A control was prepared with water added to dry soil.

Chemical analyses of test concentrations were made at the Terracon Laboratorium für Umwelt und Pestizidanalytik GmbH (Jütterborg, Germany). Vz-contaminated soil samples (10 g) were extracted using acetonitrile (Carl Roth $\mathrm{GmbH}$, Karlsruhe, Germany) in an ultrasonic bath at $40^{\circ} \mathrm{C}$ for $30 \mathrm{~min}$. Vz-concentration determination was performed by gas chromatography-mass spectrometry (GC-MS; Varian), including a $3400 \mathrm{GC}$ ion-trap MS-Detector Saturn II, an Autosampler $82008200 \mathrm{cx}$, and Saturn II GC-MS software with a NIST 2002 MS-library. BPA-contaminated soil samples $(15 \mathrm{~g})$ were extracted in Soxhlet apparatus with methanol for $3 \mathrm{~h}$. The extract was evaporated to $10 \mathrm{ml}$ by rotary vacuum evaporator $\left(40^{\circ} \mathrm{C}\right)$. BPA concentrations were determined by ultraviolet detection at $230 \mathrm{~nm}$ using a 
high-pressure liquid chromatography-photo diode array (HPLC-PDA) system (Shimadzu, Japan) equipped with a $\mathrm{C}_{18}$ column $(5 \mu \mathrm{m})$ and PDA detector SPD-M10Avp. Analytic values were within $\pm 5 \%$ of the nominal concentrations, and therefore the results are presented as nominal values.

\section{Organism Exposure}

Experimental conditions were as described previously for the $P$. scaber culturing.

\section{Adult Isopod Growth Test}

Only male adult woodlice were use to ensure that female reproductive traits did not influence the parameters assessed. In addition, animals were checked for molting stage, and only animals at the intermolt stage were used.

Twelve animals (20 $\pm 1 \mathrm{mg}$ each) per treatment were individually placed in polyethylene terephtalate (PET) boxes $(\varnothing 100 \times 50 \mathrm{~mm})$ filled with $60 \mathrm{~g}$ spiked soil and alder leaf discs $(\varnothing 10 \mathrm{~mm})$, which were added weekly, when necessary, to keep food in excess and in equal amounts for all replicates. Growth was monitored at weekly intervals for 10 weeks as described later in the text.

\section{Juvenile Isopod Growth Test}

Synchronized juvenile woodlice (weighing 4-5 mg) were used. Thirty animals per chemical concentration were separated before differentiation of secondary sexual characters to insure virginity of the animals, thus preventing reproductive activities during the experimental period. The animals were placed individually in PET boxes $(\varnothing 60 \times 30$ $\mathrm{mm}$ ) filled with $30 \mathrm{~g}$ spiked soil and alder leaf discs, which were added weekly, when necessary, to keep food in excess and in equal amounts for all replicates. Growth was determined at weekly intervals for 16 weeks as described later in the text, and sex was determined by the end of the experimental period.

Measurements, Photographs, and Image Analysis

An increase in cuticle size is a reliable sign that a crustacean has molted. The duration of $P$. scaber's molt cycle is approximately 33 days, whereas the ecdysis is a biphasic process, with the posterior and anterior part of the body molting separately within $24 \mathrm{~h}$ (Zidar et al. 1998). This timing allowed weekly inspection of the intermolt isopod, which is sufficient to identify the occurrence of ecdysis while least stressing the animal (Lemos et al. 2009a). Tested woodlice were weighed weekly and photographed under a stereo dissecting microscope. Images were then analysed using Leica Qwin image processing and analysis software. Cephalothorax width $(\mathrm{CW})$ was then measured. Growth per molting interval and the occurrence of molt was then inferred from difference of size in consecutive measurements. Animals undergoing ecdysis were recorded, undisturbed, and therefore measurements were not necessary.

\section{Statistical Analysis}

All data were checked for normality and homoscedascity. One way analysis of variance (ANOVA) with Dunnett's multiple comparison tests were employed to determine significant differences of the chemicals' concentrations relative to the control treatment. Where applicable, results are presented as mean $\pm \mathrm{SE}$. For all statistical tests the significance level was set at $p \leq 0.05$. All calculations were performed using SigmaStat software (Systat Software Inc. 2006).

\section{Results}

\section{Effects of $\mathrm{Vz}$ and BPA on Adult $P$. scaber}

No significant differences in growth per molt were found between Vz treatments and control (ANOVA, Dunnett's test for first molt: $F_{5.32}=0.341, p=0.884$; for second molt: $F_{4.29}=1.892, p=0.139$; and for third molt: $F_{3.18}=0.778$, $p=0.522$ ). Because there was $100 \%$ mortality at the highest concentration after 10 weeks of testing, only growth after the first molt could be assessed for this treatment.

After 10 weeks, control woodlice gained $83 \%$ in mass and showed an increase of $24 \%$ in size (Fig. 1a). The woodlice exposed to 10,30 , and $100 \mathrm{mg}$ a.i. $\mathrm{Vz} / \mathrm{kg}$ soil tended to increase in size and mass compared with controls, whereas a decreased in these growth parameters was visible at the highest concentration tested. The increase in the $\mathrm{CW}$ was lower and significantly different from controls exposed to $300 \mathrm{mg}$ a.i. Vz/kg soil (ANOVA, Dunnett's test, $F_{4.29}=2.941, p=0.037$ ).

Isopod mass gain after 10 weeks decreased with increasing exposure to BPA, with a NOEC of $300 \mathrm{mg} \mathrm{BPA} /$ $\mathrm{kg}$ soil (ANOVA, Dunnett's test, $F_{5.33}=3.306, p=0.018$ ), and no effects were seen in CW size increase (ANOVA, Dunnett's test, $F_{5.32}=1.582, p=0.193$ ) (Fig. 1b).

Also in BPA-exposed woodlice, there was no difference in size gain after the first molt (ANOVA, Dunnett's test, $F_{5.37}=2.284, p=0.070$ ), but at concentrations of 10 and $1000 \mathrm{mg} \mathrm{BPA} / \mathrm{kg}$ soil size gain decreased significantly at the second and third molts (ANOVA, Dunnett's test, $F_{5.35}=3.137, p=0.018$ and $F_{5.33}=3.222, p=0.018$, respectively) (Fig. 2). 

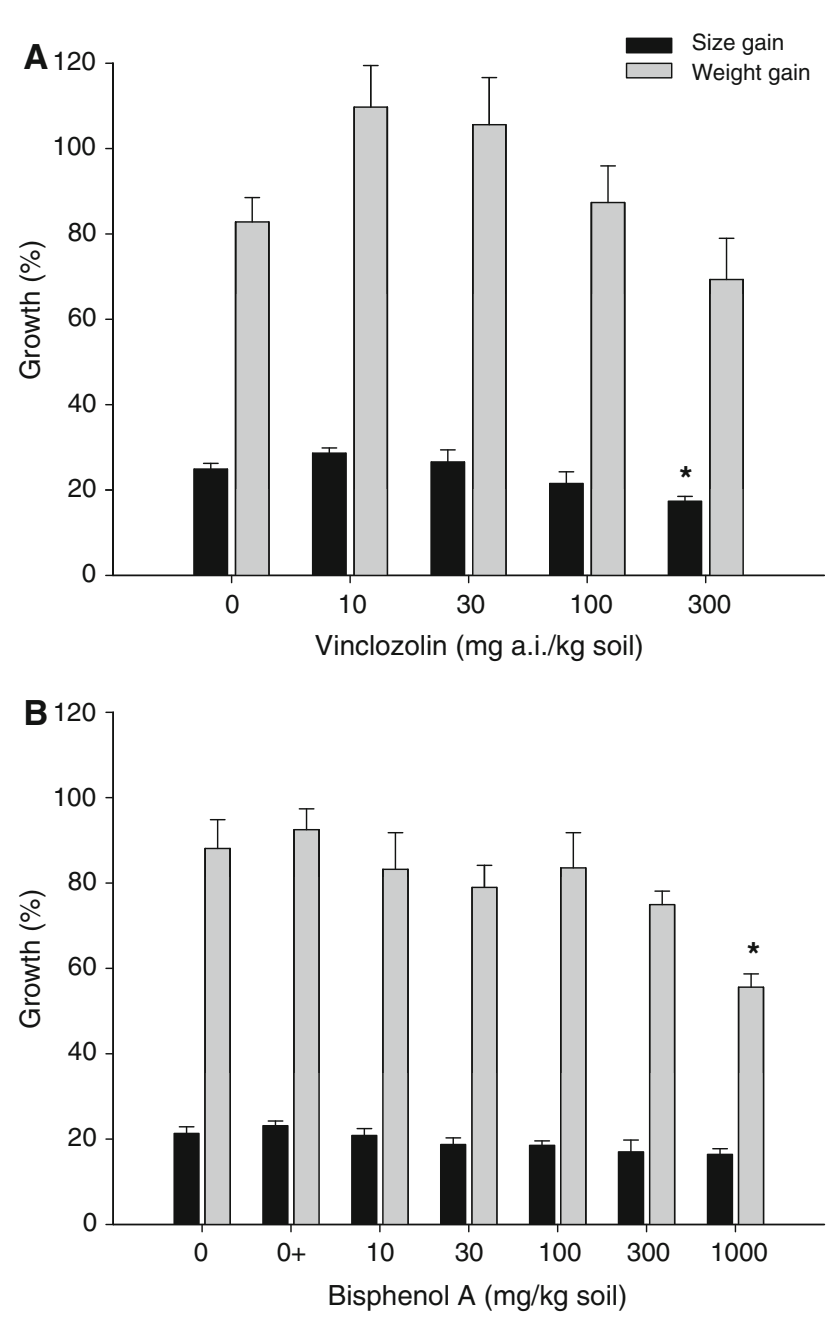

Fig. 1 Growth of adult male $P$. scaber after 10 week exposure to soil treated with a Vz and b BPA. Black bars represent size gain (final $\mathrm{CW} /$ initial $\mathrm{CW}$ ), and grey bars represent mass gain (final weight/ initial weight). $*$ Significant difference from the control at $p \leq 0.05$ (ANOVA, Dunnett's test)

\section{Effects of Vz and BPA on Juvenile P. scaber}

Juvenile growth and molting regime were monitored for 16 weeks. Most control juvenile woodlice were in the molting stage after 1 week of exposure (59\% of female and $55 \%$ of male woodlice), and $23 \%$ of female and $27 \%$ of male woodlice were in the molting stage after 2 weeks of exposure (Fig. 3b). Regarding the effects of $\mathrm{Vz}$, from the concentration of $25 \mathrm{mg}$ a.i. $\mathrm{Vz} / \mathrm{kg}$ soil onward there seemed to be a decrease in molting female woodlice in the first week. In treatments with 50 and $100 \mathrm{mg}$ a.i. Vz/kg soil, most animals molted in the second week $(55 \%$ and $67 \%$, respectively). Male woodlice showed a similar response to that observed in female woodlice but only at the highest concentration, with only $38 \%$ of the woodlice molting after 1 week of exposure (Fig. 3a).

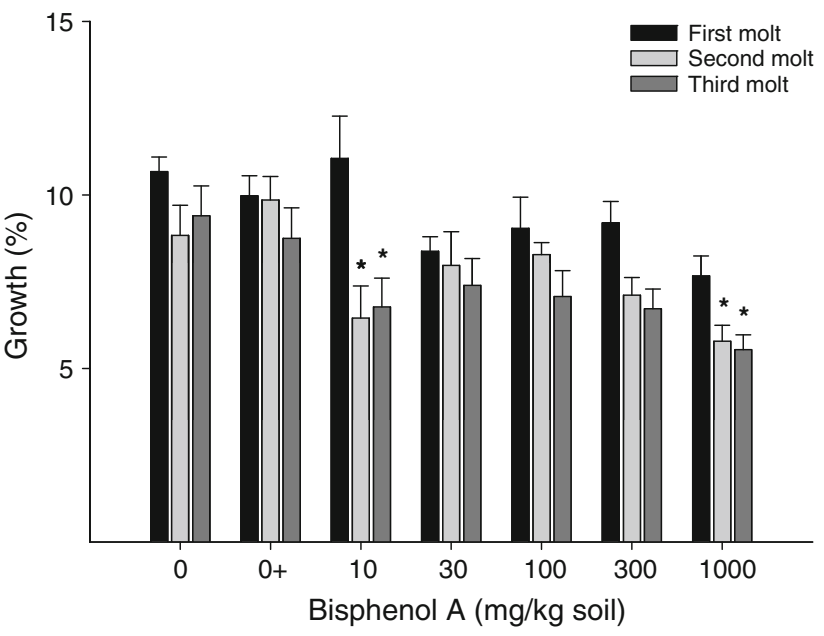

Fig. 2 Size gain over three consecutive molts of adult male $P$. scaber after exposure to BPA-contaminated soil. Results are shown as the quotient of the width of the middle segment after and before molt. * Significant difference from the solvent control at $p \leq 0.05$ (ANOVA, Dunnett's test)

The total number of molts during the 16-week testing period was also determined. The average number of molts per male and female woodlice was 3.6 and 3.9, respectively, in controls (Fig. 4). The number of molts decreased with increasing concentrations of the compound in both male and female woodlice, but differences were only significant at $100 \mathrm{mg}$ a.i. Vz/kg soil (ANOVA, Dunnett's test, $F_{5.59}=2.628, p=0.033$ and $F_{5.68}=2.659, p=0.030$, respectively; see Fig. 4).

Juveniles' size (CW) and mass gain were significantly impaired by $\mathrm{Vz}$ in both sexes (Fig. 5a, b). Size gain decreased with increasing toxicant concentrations and was significantly different at $\mathrm{Vz}$ concentration of $100 \mathrm{mg} / \mathrm{kg}$ soil compared with juvenile woodlice in nontreated soil (male and female woodlice with $14 \%$ and $16 \%$ reduction, respectively [ANOVA, Dunnett's test, males: $F_{5.80}=$ 2.647, $p=0.045$ and females: $\left.F_{5.61}=2.422, p=0.045\right]$ ). Juveniles' weight gain also decreased with increasing concentrations of $\mathrm{Vz}$, with significant differences compared with controls, at the highest concentration tested (100 mg a.i. Vz/kg soil) both for male and female woodlice (ANOVA, Dunnett's test, $F_{5.80}=2.585, p=0.036$ and $F_{5.61}=2.565, p=0.036$, respectively).

Regarding the effects observed for BPA, exposure increased the number of juveniles that molted during the first week, with $85 \%$ of the woodlice undergoing molting in this period at $300 \mathrm{mg} \mathrm{BPA} / \mathrm{kg}$ dry soil (Fig. 3c, d).

There seems to be a trend for BPA to decrease time to first molt (Fig. 3c, d), but no statistically significant differences in the number of molts were observed between treatments during the 16-week experimental period (ANOVA, Dunnett's test, $F_{5.52}=4.052, p=0.477$ for 
Fig. 3 Distribution of first molt per week of juvenile $P$. scaber exposed to soil contaminated with Vz (left) and BPA (right). $\mathbf{a}$ and $\mathbf{c}$ Male woodlice. $\mathbf{b}$ and $\mathbf{d}$ Female woodlice. Data are presented as percentage of animals that molted during each period
A

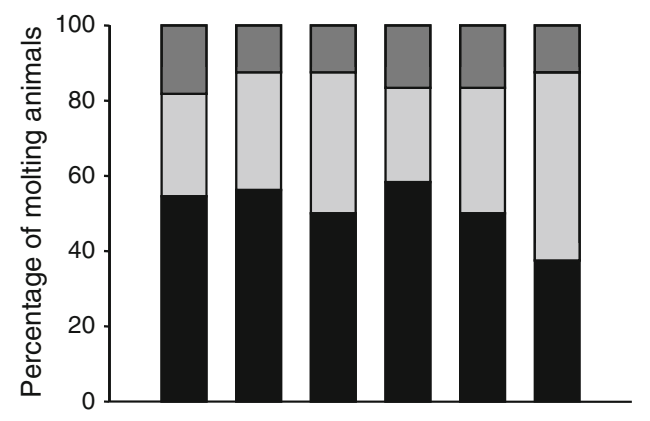

B

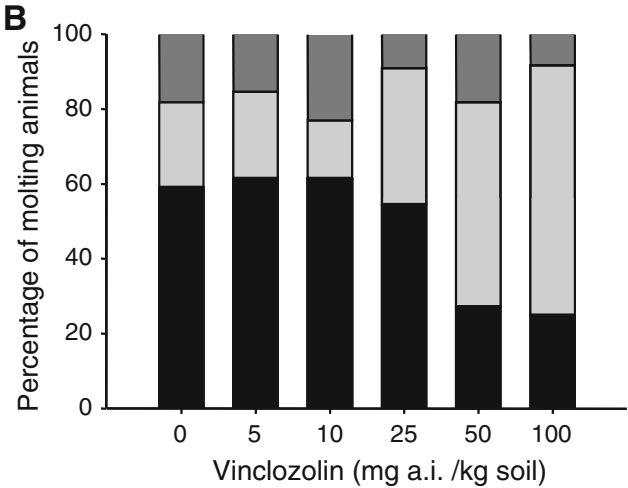

c

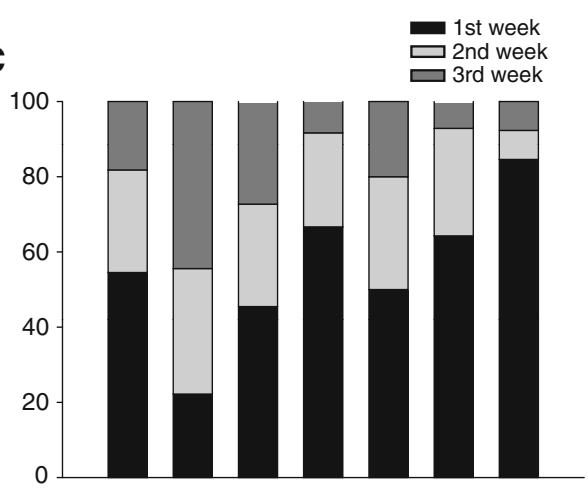

$\mathbf{D}_{100}$

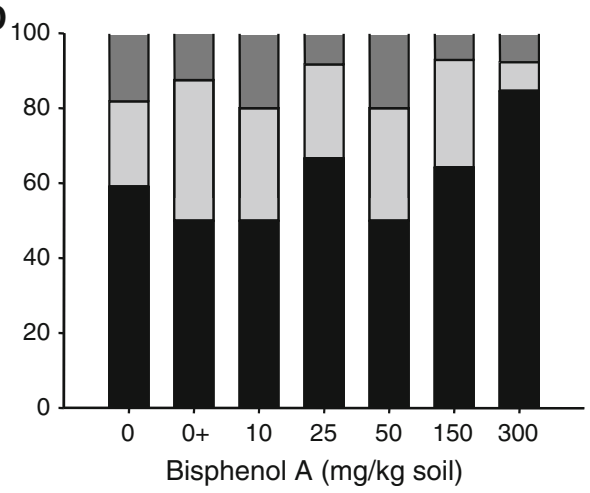

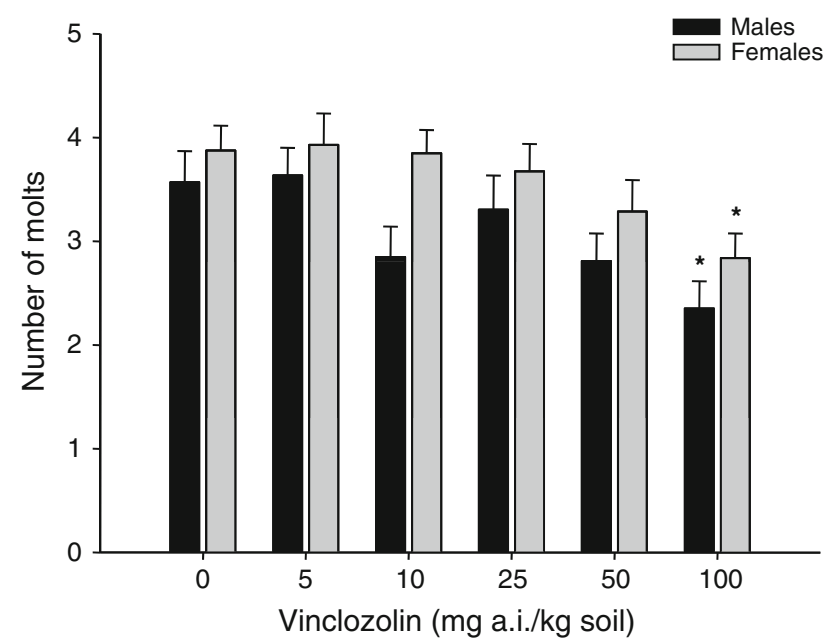

Fig. 4 Number of molts of $P$. scaber juveniles during a 16-week period of exposure to soil treated with Vz. * Significant difference from the control at $p \leq 0.05$ (ANOVA, Dunnett's test)

male and $F_{5.52}=4.052, p=0.255$ for female woodlice). Weight and size gain decreased with increasing concentrations of BPA, with an LOEC value of $25 \mathrm{mg} \mathrm{BPA} / \mathrm{kg}$ soil for size gain (ANOVA, Dunnett's test, $F_{5.52}=4.052$, $p=0.004$ ) and weight gain (ANOVA, Dunnett's test, $F_{5,52}=5.537, p<0.001$ ) for male woodlice (Fig. 5c, d). Although a significant effect was found on female size and weight gain compared with the solvent control, with a LOEC of $10 \mathrm{mg} \mathrm{BPA} / \mathrm{kg}$ soil (ANOVA, Dunnett's test,
$F_{5.64}=3.303, p=0.012$ and $F_{5.64}=6.300, p<0.001$, respectively), an irregular concentration response pattern was observed for the growth of female woodlice exposed to BPA (Fig. 5c, d).

\section{Discussion}

In a previous study, it was shown that male adult $P$. scaber molt is drastically delayed with increasing concentration of $\mathrm{Vz}$, whereas BPA exposure induces the occurrence molting (Lemos et al. 2009a). These molting perturbations were attributed to an increase of the endogenous molting hormone (20-hydroxyecdysone [20E]) concentration, which enabled the suggestion of a causal link of this impairment to ED in this class of organisms. In the same study, it was also reported that although $\mathrm{Vz}$ postpones molt and BPA induces it, both compounds similarly seemed to precipitate both sets of exposed woodlice to the premolt stage. Nevertheless, whilst for BPA-exposed woodlice the period of time undergoing premolt is normal and ecdysis happens, for Vz-exposed woodlice the levels of circulating 20E are maintained too high; thus, the necessary decrease in $20 \mathrm{E}$ concentration below the threshold value, for which the exuviation factor is released, is not attained. This prolongs the premolt stage: animals show delayed or incomplete molt, and death surmounts at higher toxicant concentrations (10-week $\mathrm{LC}_{50}$ [95\% confidence interval] 298 
Fig. 5 Growth of juvenile $P$. scaber exposed for a 16-week period to soil treated with $\mathrm{Vz}$ (left graphs) or BPA (right graphs). a and c Mass gain (final weight/initial weight). $\mathbf{b}$ and $\mathbf{d}$ Size gain (final $\mathrm{CW} /$ initial $\mathrm{CW}) . *$ Significant difference from the control at $p \leq 0.05$ (ANOVA, Dunnett's test)
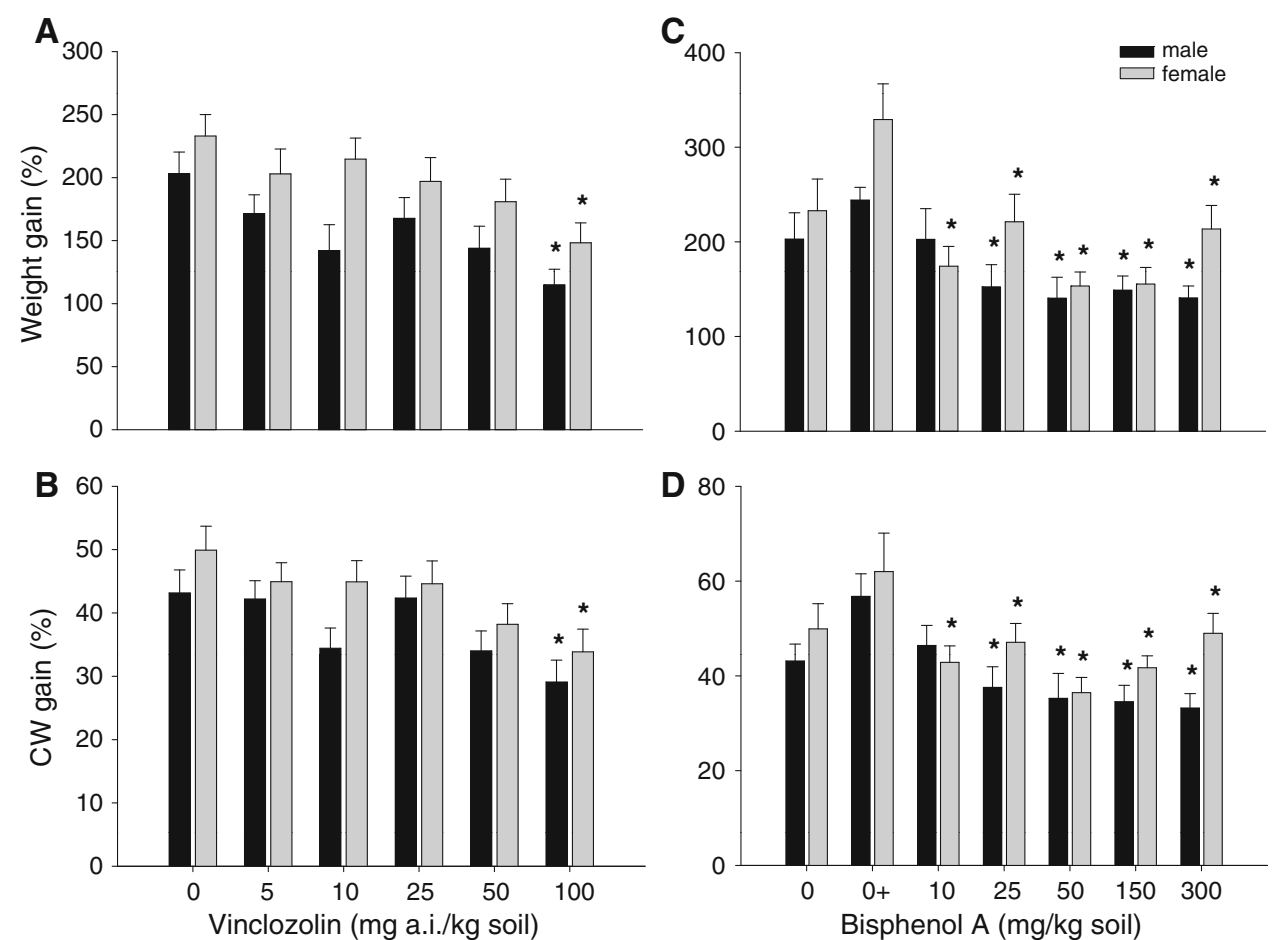

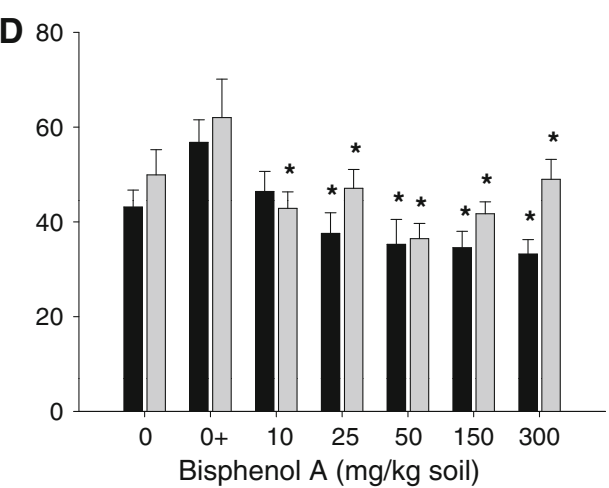

[150 to 447] $\mathrm{mg} / \mathrm{kg}$ dry soil). In the present research, it was shown that despite the different interference of the two test compounds with molting, both toxicants caused significant decreases in overall growth for adult and juvenile woodlice.

Actually, uncertainties still exist regarding the sensitivity of different genders, developmental stages, and critical periods of endocrine function in invertebrates exposed to EDCs (Rodriguez et al. 2007). The impacts of EDCs may differ according to the specific life stage at which exposure occurs (e.g., embryolarval stages, gonadal development, etc.) (deFur et al. 1999).

According to Lawlor (1976), in the woodlouse Armadillidium vulgare, total energy allocated to growth plus reproduction among reproductive female animals is equivalent to the total energy devoted to growth in nonreproductive female or male animals. This will result in decreased growth rate of reproductive female animals when included in tests and may lead to extravariability. For this reason, studies concerning toxicant effects on crustaceans should question the use of a mixed set of genders in experiments, regardless of ensuring the withdrawal of visible gravid woodlice from data sets, because these female animals are able to store sperm and later reproductive processes could be occurring, even if they are not noticed. In addition, female animals not only grow more than male animals (Vink et al. 1996), they also may have differential responses to the stressor (Weis et al. 1992).

In the present study, only male adult woodlice were used. In the case of tests with juvenile woodlice, virginity was fully assured, and separate sex sets were used. Moreover, the animals' uniform age and molt stage were also taken into account because crustaceans are more susceptible to environmental stresses during molting (Weis et al. 1992). Results show that juvenile female woodlice are more sensitive than juvenile male woodlice to BPA exposure (female LOEC $10 \mathrm{mg} \mathrm{BPA} / \mathrm{kg}$ soil and male LOEC $25 \mathrm{mg} \mathrm{BPA} / \mathrm{kg}$ soil) as evidenced by the decreased weight gain.

Adult male $P$. scaber experiments showed an $\mathrm{LC}_{50}$ (95\% confidence interval) of 910 (range 163 to 1658) $\mathrm{mg} /$ $\mathrm{kg}$ soil for BPA and 298 (150 to 447) $\mathrm{mg}$ a.i./kg soil for $\mathrm{Vz}$ after 10 weeks of exposure. In the present study, the $\mathrm{LC}_{50}$ for the effects on juvenile woodlice was $>300 \mathrm{mg} / \mathrm{kg}$ soil for $\mathrm{BPA}$ and $100 \mathrm{mg}$ a.i./kg soil for $\mathrm{Vz}$, even after 16 weeks. Therefore, the lethality of the compounds to juvenile woodlice is on the same order magnitude as for adult woodlice. Nevertheless, young woodlice seemed to respond with decreased growth at lower concentrations (LOECs of $10 \mathrm{mg} \mathrm{BPA} / \mathrm{kg}$ soil and $100 \mathrm{mg}$ a.i. Vz/kg soil) compared with adults (LOECs of $1000 \mathrm{mg} \mathrm{BPA} / \mathrm{kg}$ soil and $300 \mathrm{mg}$ a.i. $\mathrm{Vz} / \mathrm{kg}$ soil). The increased sensitivity of the juvenile life stage may be due either to easier absorption of the toxicant through their relatively larger body surface-to-volume ratio and thin cuticle or to their lower capacity to metabolize the contaminants (Fischer et al. 1997; Lemos et al. 2010a). Therefore, chronic toxicity assessment should to be adapted to the life span of the woodlouse, from manca to fully reproductive adult, as proposed by Samsøe-Petersen (1990). 
Although female woodlice grew significantly less when exposed to BPA, they did not show a regular concentrationrelated response to the toxicant. Female-biased sex ratios were reported for juvenile $P$. scaber exposed to this xenoestrogen (Lemos et al. 2009a). The erratic female response to BPA found here may be due to this phenomenon of feminization and the high variability of response that these female woodlice show because they might be either phenotypic/genotypic: female/female or female/ male. Juvenile male woodlice grew less than the control from $25 \mathrm{mg} \mathrm{BPA} / \mathrm{kg}$ soil onward. The quotient of the $\mathrm{LC}_{50}$ value and the geometric mean of the NOEC and LOEC (LeBlanc 2004) provides us with an acute-to-chronic ratio (ACR) for BPA exposure as follows: (ACR: $>300$ / $\sqrt{10 \times 25}$ ) $>19$. Mu et al. (2005) found an ACR value of 12 for Daphnia magna exposed to BPA. An ACR value $>10$ is typically indicative of chronic toxicity elicited by a mechanism distinct from that responsible for acute toxicity.

The upregulation of arginine kinase, an enzyme involved in cellular energy metabolism, in the hepatopancreas of Vz- and BPA-exposed woodlice, which was reported earlier (Lemos et al. 2010b), shows a clear detoxification effort and, consequently, less energetic allocation in physiologic processes, such as growth.

Fukuhori et al. (2005) suggested that the adverse effects seen at high BPA concentrations are the result of systemic toxicity and may not be due to the estrogenic function of the compound. Hence, the effects seen at lower concentrations (Fig. 2) might be from a different origin from those effects seen at higher concentrations. Therefore, further testing should consider other approaches, such as the "omics" technologies, that might distinguish the effects of systemic toxicity and those that arise from ED at lower concentrations (Lemos et al. 2009b). Thus, it is crucial that in an earlier stage of the ED study, the range of concentrations tested is stretched and the maximum tolerated concentration (for which effects are not directly associated with lethality) distinguished (Hutchinson et al. 2009).

\section{Conclusion}

Both BPA and Vz elicited overall growth impairment in a terrestrial isopod. Moreover, regarding BPA exposure, results showed that female woodlice are the most sensitive sex to this toxicant and that juvenile woodlice, although having $\mathrm{LC}_{50}$ values (close to the ones for adults), showed increased sensitivity to the toxicants' chronic effects.

Therefore, based in the current results, full life-cycle tests, with both male and female isoopods, are recommend to provide valuable information regarding differential dose responses, effects, and threshold values, which can impair population dynamics by affecting isopod development.
Acknowledgments M. F. L. Lemos was supported by Fundação Para a Ciência e Tecnologia (BD/13868/2003). Parts of this work were supported by FCT Project Grant Reference No. PTDC/BIABDE/75690/2006.

Open Access This article is distributed under the terms of the Creative Commons Attribution Noncommercial License which permits any noncommercial use, distribution, and reproduction in any medium, provided the original author(s) and source are credited.

\section{References}

Barata C, Porte C, Baird DJ (2004) Experimental designs to assess endocrine disrupting effects in invertebrates̄a review. Ecotoxicology 13:511-517

Bursztyka J, Debrauwer L, Perdu E, Jouanin I, Jaeg JP, Cravedi JP (2008) Biotransformation of vinclozolin in rat precision-cut liver vices: comparison with in vivo metabolic pattern. J Agric Food Chem 56:4832-4839

deFur PL, Crane M, Ingersoll C, Tattersfield L (1999) Endocrine disruption in invertebrates: Endocrinology, testing, and assessment. In: Proceeding of the workshops on endocrine disruption in invertebrates, Noordwijkerhout, The Netherlands. SETAC, Pensacola, FL, 12-15 Dec 1998

Drobne D (1997) Terrestrial isopods a good choice for toxicity testing of pollutants in the terrestrial environment. Environ Toxicol Chem 16:1159-1164

European Commission (1999) Communication from the Commission to the Council and the European Parliament. Community strategy for endocrine disrupters. COM (1999) 706. Commission of the European Communities, Brussels, Belgium

Fischer E, Farkas S, Hornung E, Past T (1997) Sublethal effects of an organophosphorous insecticide, dimethoate, on the isopod Porcellio scaber Latr. Comp Biochem Physiol C 116:61-166

Fukuhori N, Kitano M, Kimura H (2005) Toxic effects of bisphenol A on sexual and asexual reproduction in Hydra oligactis. Arch Environ Contam Toxicol 48:495-500

Hutchinson TH, Bögi C, Winter MJ, Owens JW (2009) Benefits of the maximum tolerated dose (MTD) and maximum tolerated concentration (MTC) concept in aquatic toxicology. Aquat Toxicol 91:197-202

Lawlor LR (1976) Molting, growth and reproductive strategies in terrestrial isopod, Armadillidium vulgare. Ecology 57:1179-1194

LeBlanc GA (2004) Basics of environmental toxicology. In: Hodgson E (ed) A textbook of modern toxicology, 3rd edn. John Wiley \& Sons, Inc., pp 463-478

LeBlanc GA (2007) Crustacean endocrine toxicology: a review. Ecotoxicology 16(1):61-81. doi:10.1007/s10646-006-0115-z

Lee HJ, Chattopadhyay S, Gong EY, Ahn RS, Lee K (2003) Antiandrogenic effects of bisphenol A and nonylphenol on the function of androgen receptor. Toxicol Sci 75:40-46

Lemos M, van Gestel C, Soares A (2009a) Endocrine disruption in a terrestrial isopod under exposure to bisphenol A and vinclozolin. J Soils Sediments 9:492-500

Lemos MFL, Soares AMVM, Correia AC, Esteves AC (2009b) Proteins in ecotoxicologȳhow, why, and why not? Proteomics [Epub ahead of print]. doi:10.1002/pmic.200900470

Lemos MFL, Van Gestel CAM, Soares AMVM (2010a) Reproductive toxicity of the endocrine disrupters, bisphenol A and vinclozolin, in the terrestrial isopod Porcellio scaber. Chemosphere 78:907913. doi:10.1016/j.chemosphere.2010.01.055

Lemos MFL, Esteves AC, Samyn B, Timperman I, Correia A, Van Gestel CAM et al (2010b) Protein differential expression 
induced by EDCs in a terrestrial isopod. Chemosphere. doi: 10.1016/j.chemosphere.2010.01.055

Mu X, Rider CV, Hwang GS, Hoy H, LeBlanc GA (2005) Covert signal disruption: anti-ecdysteroidal activity of bisphenol A involves cross talk between signaling pathways. Environ Toxicol Chem 24:146-152

Oehlmann J, Schulte-Oehlmann U (2003) Endocrine disruption in invertebrates. Pure Appl Chem 75:2207-2218

Oetken M, Bachmann J, Schulte-Oehlmann U, Oehlmann J (2004) Evidence for endocrine disruption in invertebrates. Int Rev Cytol 236:1-44

Okada H, Tokunaga T, Liu XH, Takayanagi S, Matsushima A, Shimohigashi Y (2008) Direct evidence revealing structural elements essential for the high binding ability of bisphenol A to human estrogen-related receptor-gamma. Environ Health Perspect 116:32-38

Porte C, Janer G, Lorusso LC, Ortiz-Zarragoitia M, Cajaraville MP, Fossi MC et al (2006) Endocrine disruptors in marine organisms: approaches and perspectives. Comp Biochem Physiol C 143:303-315

Rodriguez EM, Medesani DA, Fingerman M (2007) Endocrine disruption in crustaceans due to pollutants: a review. Comp Biochem Physiol A 146:661-671

Samsøe-Petersen L (1990) Sequences of standard methods to test effects of chemicals on terrestrial arthropods. Ecotoxicol Environ Saf 19:310-319

Systat Software Inc. (2006) SigmaStat for windows (version 3.5). Chicago, IL, USA

Vink K, Kurniawati TA (1996) Iteroparous reproduction, body growth and energy reserves in a tropical population of the isopod, Porcellionides pruinosus. Pedobiologia 40:467-476

Weis JS, Cristini A, Rao KR (1992) Effects of pollutants on molting and regeneration in crustacea. Am Zool 32:495-500

Zidar P, Drobne D, Strus J (1998) Determination of moult stages of Porcellio scaber (Isopoda) for routine use. Crustaceana 71:646654 